\title{
THE ENHANCEMENT OF CULTURAL TOURISM ROUTES IN THE LANNA REGION OF NORTHERN THAILAND
}

Sudarat Auttarat, ${ }^{*}$ Korawan Sangkakorn \& Sansanee Krajangchom**

${ }^{*}$ First author, ${ }^{* *}$ corresponding author

Centre of Tourism Research and Development, Social Research Institute, Chiang

Mai University, Thailand

(sauttarat343@gmail.com, korawana@gmail.com, skrajangchom318@gmail.com)

DOI: https://doi.org/10.22452/jati.vol26no1.6

\begin{abstract}
The Lanna region is a former kingdom in the area of modern-day Northern Thailand that also once extended into Myanmar, Laos and China. Currently, Lanna culture is used as a selling point for tourism to Northern Thailand, but there are problems with the way tourism routes are designed and packaged. This paper aims to promote the architectural value of Lanna culture through the development of tourism routes. The qualitative investigation assesses existing Lanna tourist routes in Northern Thailand and develops guidelines for the development of cultural tourism in the region. Initial research led to the identification of 35 sites for in-depth evaluation. Data was gathered by document research, field evaluation and interviews following criteria co-developed by Chulalongkorn University and the Department of Tourism (2007). Findings indicated that destinations in Northern Thailand are of a good standard but should be developed in terms of tourism support and management. The researchers produced guidelines for the development of individual attractions and designed cultural routes according to provincial boundaries and periodic themes.
\end{abstract}

Keywords: cultural tourism, Lanna architecture, tourism management, tourism routes

\section{Introduction}

Through a combination of better education, greater publicity and diversity of opportunities, cultural tourism has become increasingly popular in the past decade, accounting for over $39 \%$ of worldwide international tourist arrivals (Richards, 2018). Cultural tourism is very simply defined as tourism with the objective of learning and understanding the value and importance of cultural resources in tourist destinations (Mousavi, Doratli, Mousavi, \& Moradiahari, 2016). Countries in Asia are important destinations for cultural tourists because 
there is a significant number of cultural heritage sites with the potential to support large numbers of tourists (Fang, 2020). Benefitting from the draw of its rich natural resources, strong price competitiveness and diverse cultural resources, Thailand now occupies a higher place in the World Economic Forum's Travel and Tourism Competitiveness Index, an annual review that benchmarks the competitiveness of 140 travel and tourism economies and measures competitiveness on a global stage (Calderwood \& Soshkin, 2019). The Thai government has recognised this and placed further importance on the promotion and development of cultural tourism. Given their former membership of the Lanna Kingdom, an historic state in Southeast Asia from the 13th to 18th centuries, the provinces in the upper north of Thailand have been designated as part of a Lanna civilisation tourist route that can link tourism in Thailand with the neighbouring countries of Lao People's Democratic Republic (Laos PDR), the Republic of the Union of Myanmar and the People's Republic of China (Piboonrungroj \& Sangkakorn, 2013).

Sangkakorn (2018) examined potential tourist routes related to the Lanna civilisation in Northern Thailand by considering three factors: transportation networks, acceptance by leading travel organisations and the value of cultural resources in the travel area. Of all cultural tourism routes studied at the provincial and interprovincial levels in upper Northern Thailand, one in six enabled tourists to study significant historical and cultural features by providing information to tell the story of historical social and human development. These locations were found to relate the site to its culture, knowledge, and value to society by reflecting the lifestyle, economic conditions and customs of people in each historical period. On behalf of Thailand Science Research and Innovation, Sangkakorn designed three main routes to highlight the religious and domestic architecture that reflected the story of the Lanna kingdom in various eras: Lanna Art and Architecture Route, Myanmar-Bagan-Shan Art and Architecture Route and Lanna-Lan Xang Art and Architecture Route.

Sangkakorn's routes were designed to promote the cultural value of tourist attractions and develop tourism in the region. Designated tourist routes must attract tourist attention and have sufficient potential to meet market needs. Therefore, in order to raise the standard of cultural tourism routes, this study aims to assess the current situation of the routes designed by Sangkakorn in Northern Thailand and develop guidelines for the promotion and development of further cultural tourism routes that encourage tourists to appreciate the value of Lanna architecture. It is hoped that this will raise the level of cultural tourism routes and programs concerning Lanna architecture and raise awareness of the value of Lanna architectural knowledge, which can be applied by all sectors to determine the direction of tourism development in the country. 


\section{Literature Review}

Murray and Graham (1997) explained that tourism routes 'combine cultural consumption with points of sale and are inextricably linked - as with all heritage tourism - to a continuous re-imaging of place and culture that draws inspiration from nostalgia, memory and tradition' (Murray \& Graham, 1997, p. 514). The development of cultural tourism routes is a European idea. First mooted in the 1960s, cultural routes were originally intended to promote destinations in single or multiple nations that shared a common heritage, whether historical, social or otherwise (Briedenham and Wickens, 2004). One of the first manifestations of such a route was the Santiago de Compostela Pilgrim Ways (Council of Europe, 2002). There are now over 30 official Cultural Routes of the Council of Europe and countless imitations across the globe, ranging in theme from pilgrim trails and trading routes to culinary odysseys (Urošević \& Kaurin, 2017).

The potential of tourism routes for the development of tourism in rural areas has been well documented since this kind of initiative became more prominent at the turn of the Millennium (Briedenhann \& Wickens, 2004). As global interest in cultural tourism grows, cultural tourist routes are being increasingly explored as ways to promote otherwise unvisited regions on the mainstream tourist path (Schuhbert, Thees, Herbold, Weinreiter, \& Kantsperger, 2020). Capacity to develop tourist routes is not purely determined by the development status of an individual country. Cross-sector cooperation and national coordination have been recognised as areas for development in a number of developed countries (Festa, Shams, Metallo, \& Cuomo, 2020; Olsen, 2003). In fact, local government weaknesses are cited as a main reason for the ineffectiveness of tourism routes in developing the economy of surrounding communities (Devkota, Paudel, \& Bhandari, 2020; Rogerson, 2007).

In 2018, Thailand Science Research and Innovation conducted a research project to study the potential of Northern Thai provinces to support cultural tourism (Sangkakorn, 2018). Locations in Chiang Mai $(n=88)$, Chiang Rai $(n=71)$, Lamphun $(n=22)$, Lampang $(n=27)$, Phrae $(n=15)$, Nan $(n=13)$ and Phayao $(n=29)$ were surveyed and evaluated. The findings showed that only three locations in Chiang Mai and one location in Nan had high potential to support cultural tourism. Of the remainder, almost all had moderate potential. The weaknesses in need of addressing were found to be publicity and public relations, facilities and tourism standard certification. The element of 'access to tourist attractions' in Chiang Mai was the only component with the potential to support high levels of cultural tourism. This reflects the well-developed transportation system in Chiang Mai Province, which can efficiently support travel to cultural tourist sites in the area. Although the majority of big city Thai travellers visit tourist destinations for 
relaxation, 'self-drive tourism' is a big part of the domestic Thai tourist market outside the main resorts (Phuwanatwichit, Songthanapithak, Srirat, \& Sangkam, 2019). Studies of self-drive tourists in northern Thailand have found that their planned routes are determined by facilities and accommodations, while the attractions contribute most to their en-route satisfaction (Yiamjanya, 2019). Similar conclusions were drawn by research in the Northeast of Thailand that indicated tourist experiences on pre-planned routes are enhanced by interaction with the local culture and, especially, the environment (Sirikudta, Archarungroj, \& Sirisuthikul, 2019). The biggest factor in tourist satisfaction of unplanned driving routes was found to be convenience stops and facilities (Denstadli \& Jacobsen, 2011). Whilst the importance of good governance and cross-sector cooperation should not be understated, these researchers feel is clear that facilities and cultural experiences are significant contributors to the overall tourist impression of tourist routes in Thailand.

\section{Methodology}

This qualitative investigation gathered data from document analysis and action research. The research population consisted of community representatives in the tourist destinations, government agencies, including representatives from local administrative organisations in the area, representatives from provincial offices and representatives from national authorities, and representatives of the private sector, including representatives of the tourism business association, tourism business operators and representatives of tourism associations. The variables for this investigation were: 1) the situation of cultural tourism for learning the value of Lanna architecture; 2) the architectural value of the Lanna civilisation routes in Upper Northern Thailand, which are the Lanna Art and Architecture Route (consisting of tourist attractions in Chiang Rai, Chiang Mai, Lamphun and Lampang provinces) and the Lanna-Lan Xang Art and Architecture Route (consisting of tourist attractions in Phrae, Nan and Phayao provinces).

This study employed a participatory action research methodology and the researcher focused on appreciation-influence-control (A-I-C) activities, namely knowledge creation (A), the process of influence (I) and the process of creating a control (C). This method gives all sectors the opportunity to share knowledge, experience and information to enable the researcher to understand the conditions, limitations, needs and potential of various concerned parties. This enabled the research results to be applied to solve problems and determine development guidelines in line with the actual needs of the community. This research is needed to encourage participation of all sectors in the formulation and approach of architectural tourism in the Lanna area. 
Initially, a survey was conducted to gather information concerning the general characteristics of the community, culture, traditions, way of life and architectural heritage. Then site evaluation was conducted to assess the potential of participatory architectural tourism. The researcher assessed the development potential of architectural tourist attractions using an assessment guide codeveloped by Chulalongkorn University and the Department of Tourism (2007). There were three evaluation components: 1) physical potential of tourist destination; 2) potential for tourism support; and 3) management. Scores were recorded on an evaluation form. Each destination was given a score out of 100, with 81 and over considered excellent, 71-80 deemed very good, 61-70 considered good, 51-60 deemed satisfactory, and a score of 50 or less judged to be unsatisfactory.

Primary data was also collected from interviews with informants who were selected using a purposive sampling method. Interview data was examined and subsequently verified by triangulation. Secondary data was gathered from various documents, including books and theses, to enrich the study. The entire research process was conducted in twelve steps: 1) Tourist destinations were identified, based on the two research variables; 2) A review of literature was conducted from academic documents and research related to the situation of cultural tourism for learning the value of architecture in the Lanna civilisation; 3) Cultural tourist destinations were surveyed to learn about the architectural value of the Lanna civilisation. In addition, a brainstorming session was conducted with experts, entrepreneurs and relevant officials, both from the public and private sector, to assess the cultural tourism situation for learning architectural value in Lanna civilisation tourism routes; 4 ) The cultural tourism situation for learning the value of architecture in the Lanna civilisation route was summarised; 5) Smallgroup meetings and in-depth interviews were organised with informants from all relevant sectors in the area to jointly analyse ways to promote and develop cultural tourism and learn the architectural value of the Lanna civilisation; 6) Guidelines for promotion and development of cultural tourism in tourist routes were analysed in order to upgrade cultural tourism routes in the Lanna civilisation; 7) A cultural tourism route program was established to promote architectural value in the Lanna civilisation; 8) A meeting was organised with representatives from all relevant sectors in the area to reflect and discuss the cultural tourism route program; 9) The cultural tourism route program was concluded; 10) Results and lessons learned were processed; 11) A forum was arranged for the presentation of research results; 12) Research findings were presented. 


\section{Results}

For the current research project, cultural tourist attractions with specific archaeological and architectural value were selected on two of the Lanna civilisation routes, namely the Lanna Art and Architecture Route (consisting of tourist attractions in Chiang Rai, Chiang Mai, Lamphun and Lampang) and the Lanna-Lan Xang Art and Architecture Route (consisting of tourist attractions in Phrae, Nan and Phayao provinces). Research was specifically conducted on archaeological and architectural sites in Chiang Mai $(n=56)$, Chiang Rai $(n=43)$, Lamphun ( $\mathrm{n}=15)$, Lampang $(\mathrm{n}=18)$, Phrae $(\mathrm{n}=3)$, Nan $(\mathrm{n}=8)$ and Phayao $(\mathrm{n}=17)$, and only at outstanding sites in the areas of history, Lanna architecture and education about the value of Lanna architecture.

Following further refinement of cultural tourist sites based on the criteria given above, an in-depth study of the cultural tourism situation was conducted at each destination with five Lanna architectural experts, community participants and local tourism managers. The potential of each destination was assessed using the evaluation form outlined above. In addition, in-depth interviews were conducted with tourist administrators and community representatives in tourist areas. The two main discussion points of interviews were 1) the problems with development of tourist attractions to support cultural tourism and 2) community participation in tourism destination management. Results from surveys and interviews have been summarised by province below (Table 1).

Table 1: Summary of Cultural Tourist Attraction Potential in Seven Northern Thai Provinces

\begin{tabular}{|l|c|l|l|l|l|l|l|l|l|}
\hline Factor & $\begin{array}{l}\text { Maximum } \\
\text { Points }\end{array}$ & $\begin{array}{l}\text { Chiang } \\
\text { Mai }\end{array}$ & $\begin{array}{l}\text { Chaing } \\
\text { Rai }\end{array}$ & Lamphun & Lampang & Phrae & Nan & Phayao & Average \\
\hline $\begin{array}{l}\text { Physical } \\
\text { Potential of } \\
\text { Tourist } \\
\text { Destination }\end{array}$ & 50 & 34.6 & 29.3 & 32.8 & 34.3 & 34.2 & 35.1 & 27.8 & 32.7 \\
\hline $\begin{array}{l}\text { Potential for } \\
\text { Tourism } \\
\text { Support }\end{array}$ & 10 & 7.8 & 7.3 & 6.3 & 6.1 & 6.4 & 8.2 & 6.2 & 7.0 \\
\hline Management & 40 & 28.7 & 27.0 & 20.8 & 21.1 & 24.8 & 27.3 & 19.4 & 24.4 \\
\hline Total & 100 & 71.1 & 63.6 & 59.8 & 61.6 & 65.4 & 76.1 & 53.4 & 64.1 \\
\hline
\end{tabular}


The seven cultural tourist attractions selected for learning the value of Lanna architecture in Chiang Mai Province were Wat Chiang Mai, Khum Chao Burirat House, Wat Ket Karam, Wat Prasart, Wat Phra That Doi Suthep, Wat Phra Singh and Wat Don Kwen. The locations scored an average of 71.1, which is very good. It was found that further development of public relations and management would enhance the potential of tourist destinations in the province.

The three cultural tourist attractions selected for learning the value of Lanna architecture in Chiang Rai Province were Baan Dam Museum, Wat Phra Kaew and Wat Rong Khun. The locations scored an average of 63.6, which is good. In order to elevate the potential of destinations in Chiang Rai, respondents agreed that there should be site maintenance and more systematic tourism management.

The seven cultural tourist attractions selected for learning the value of Lanna architecture in Lampang Province were Kat Kong Ta (Kong Ta Market), Baan Sao Nak, Thai Bank Museum, Baan Pong Nak (Military Museum), Wat Phra That Lampang Luang, Wat Sela Rattanapaphatharam (Wat Lai Hin Luang) and Wat Pong Sanuk Nuea. The locations scored an average of 61.6, which is good. Inefficient management and tourism support remain obstacles to higher scores in Lampang Province.

The four cultural tourist attractions selected for learning the value of Lanna architecture in Lamphun Province were Mueang Lamphun Community Museum, Wat Jam Thewi, Wat Phra That Hariphunchai Woramahawihan and Wat Phra Yuen. The locations scored an average of 59.8, which is at a moderate level. The destinations in Lamphun Province were found to be lacking adequate public relations, management procedures and tourism support facilities.

The five cultural tourist attractions selected for learning the value of Lanna architecture in Phrae Province were Khum Chao Luang Mueang Phrae, Khum Wichai Racha, Baan Wong Buri, Teak Museum and Wat Jom Sawan. The location scored an average of 65.4, which is good. Although there are well-implemented foundations for cultural tourism, especially for learning the architectural value of Lanna historical sites, tourism support in the province could be further developed.

The five cultural tourist attractions selected for learning the value of Lanna architecture in Nan Province were: Wat Don Laeng, Wat Phra That Chae Haeng (Phra Aram Luang), Wat Phumin, Wat Nong Bua and Hong Chao Fong Kham. The locations scored an average of 76.1, which is very good. Although the tourist attractions in Nan Province have been well cared for and maintained, there remains capacity to enhance the educational value of the sites.

The four cultural tourist attractions selected for learning the value of Lanna architecture in Phayao Province were Wiang Lor Ancient Site, Huan Thai Lue Ban Van, Ruen Thai Lue Mae Saengda and Wat Nantaram. The locations 
scored an average of 53.4, which is at a moderate level. It was found that all aspects of the destinations and their management should be developed.

Overall, destinations on the cultural tourism routes of the Lanna Civilisation scored 64.1, which is good. Nevertheless, promotion and development of cultural tourism is necessary in all provinces to elevate the potential of tourist destinations to very good and excellent levels, respectively. This is especially true for the categories of tourism support and management.

\section{Development of Lanna Architectural Sites for Cultural Tourism in Northeastern Thailand}

Three locations had outstanding results for cultural tourism development potential. These were Khum Chao Luang Mueang Phrae, Wat Phra That Chae Haeng and Wat Nong Bua. These sites were most ready to accept tourists and provide education in the value of Lanna architecture. Their physical characteristics were attractive; there was good tourism support and effective management. However, all three locations were found to be at a crossroads of development. During peak times, their tourism resources were all used to the point of saturation. There is also the likelihood that, without further development, the quality of the tourism package may decrease in the future.

These three destinations have built their strong position over years of accumulated cultural heritage and experience. There has been continuous development to spread awareness to the public and utilise stories that empower local people as owners. In the communities surrounding these three attractions, tourism resources have a symbolic spiritual value. In all three locations, community representatives support tourism activities. The immediate area for development of the sites is communication. More specifically, there should be more thorough communication of the links between architecture, history, society and communities. It is suggested that this can be achieved with organisation of more cultural activities and expansion of academic networks that provide opportunities for personnel in the community to add new knowledge to tourism management.

Following the evaluation, eight locations were deemed 'very good' and nine further locations were deemed 'good'. These sites had a high level of physical attractiveness, a few limitations in tourism support and significant managerial problems. Nan Province in particular has benefitted from the initiatives of the Designated Areas for Sustainable Tourism Administration (DASTA), which is a government branch charged with the development of sustainable tourism and community income distribution. The problems found in these seventeen locations arise from external factors. In all of the destinations studied, the national 
government and religious institutions coordinate development centrally. As a result, significant limitations are caused by a lack of cooperation between tourist sites and local communities. This centralised development results in an inconsistent development model because the community does not directly participate in the development plan. There is therefore an urgent need to address the problem of tourist attraction development by encouraging close cooperation between government agencies, private organisations and local organisations. These groups should support and manage budget policies and personnel issues together.

The remainder of attractions were found to have a moderate level of tourism potential. These locations had limitations in all aspects but a number of these require a common development strategy. The attractions in this group must be developed with the value and identity of local architecture at the centre. It is essential to show beauty in its original form or with minimal modifications that are consistent with the history and community. There must be development of an organisation to conserve and preserve the tourist attractions, whilst simultaneously organising sustainable tourist activities that are not intrusive on the local environment. Furthermore, any developed activities should be educationally valuable and encourage tourists to stay at the site for longer periods. With this in mind, basic facilities, such as water, electricity, roads, accommodation and restrooms must be modernised and adapted for current tourism standards. These should be continuously developed in the future. Of course, this is impractical without the cooperation of multiple organisations, not least due to budget restrictions. Hence, the cooperation of government, private and local organisations is crucial for establishment, support and management of budget policies and personnel development.

Management was found to be a significant failing in all studied attractions. Recommendations for the management of tourist sites by research informants focused on six areas: management of preserving and rehabilitating architectural attractions, management of local architecture use, monitoring and assessment of tourism-related changes, service management, activity management and awareness management. Respondents recommended a consistent attitude towards maintenance and improvement of local architecture, the environment, and important historical places within tourist attractions. To reduce any negative impact on the tourist sites, it was found that site zoning should be implemented. Furthermore, time periods should be set for visits to local architectural destinations, both by time of day and season, while the number of tourists permitted to visit should be restricted to suit the potential of the area and services available. Respondents felt that there should be a plan to monitor and assess the 
impact of tourism-related changes, and to monitor and analyse the impact of tourism. This includes operations to improve and solve problems that occur and the continuation of existing operations. Given the importance of tourism support facilities, there must be specific management of services and utilities for tourists, with basic services provided for tourists, such as adequate numbers of service personnel. There must be a system to ensure the safety of life and property of tourists. Basic buildings and utilities must also be managed better in order to facilitate a harmonious relationship between tourism and local architecture. Furthermore, there must be adequate and hygienic food and nutrition management, and systematic accommodation management for tourists. It was agreed by informants that tourism activities must take into account the impact on local architecture and the environment, including the impact on local lifestyle, traditions and cultures. Importantly, activities and operations should be organised that provide knowledge and disseminate information to tourists, tour staff, entrepreneurs and the surrounding community. By developing personnel with knowledge of local architecture, employing data centre staff and developing various types of media to provide information to tourists, the attractions will become truly valuable in the dissemination of Lanna heritage.

It is of crucial importance that local communities participate in the management of local architectural tourism. Participation requires continuous development, beginning with participation in activities and extending to the planning and implementation of the development and conservation of tourist attractions. The community should benefit from local architectural tourism, both directly and indirectly. This will encourage continued and increased participation.

\section{Creating a Cultural Tourism Route Program for Learning the Value of Architecture in the Lanna Civilisation Route}

As the final step of the investigation, the researcher developed a series of tourist routes that incorporated architectural sites from the seven provinces according to their historical period. Working with locals in northern Thailand, the architecture found in the area was divided by architectural period. Within the two predetermined civilisation routes, Lanna and Lanna-LanXang, routes were developed along distinct periodic lines: 1) Pre-Lanna (before the creation of Chiang Mai), 2) Lanna Kingdom (from the establishment of Chiang Mai to the end of the Mangrai dynasty, 1296-1558), 3) Siamese and Western Influenced Lanna (the period when Chiang Mai was integrated into Siam in the era of Rama V and adopted Siamese architectural influences as well as Western influence from immigrants, missionaries and traders), and 4) Contemporary Lanna (Modern day when new buildings are constructed by contemporary artisans in Lanna and Lan 
Xang architectural styles). These routes were created to refine the options available to cultural tourists in Northern Thailand, to facilitate interprovincial networking, and to encourage repeated tourist visits.

Moreover, rather than purely promoting interprovincial routes that highlight landmark attractions, the researcher also created a selection of provincial routes that allow the cultural tourist to experience a broader selection of Lanna architecture within each province and forge a deeper understanding of the civilisation. These learning paths highlight the architectural value of Lanna structures but incorporate more components than the interprovincial routes allow. These encourage the tourist to admire the architecture alongside religious buildings, houses and shops that reflect the story and way of life of Lanna in different eras. The primary tourist attractions offer examples of outstanding artistic and architectural features, but the surroundings offer an equally valuable insight into the Lanna and Lan Xang Kingdoms. There remain links between provinces in Northern Thailand and the larger, interprovincial routes are still suitable for tourists wishing to undertake a whistle-stop tour of the region. The seven provincial routes developed in this study are intended to create a cultural tourism network for preservation of local architecture that simultaneously links provinces and strengthens local participation.

\section{Discussion}

The scale of interprovincial routes may prove a factor in limiting the success of their impact because they require the cooperation of a greater number of components (Mei, Lerfald, \& Brătå, 2017). This was identified as a weakness of the three existing Lanna architectural routes and even with smaller scale tourism management at individual sites. Actually, the Thai government is recognised as an active participant in the management of national tourism when compared to other countries (Calderwood \& Soshkin, 2019). There is significant legislation and numerous incentive projects to stimulate tourism within the country, which is a large part of the Thai economy (Wattanacharoensil \& Schuckert, 2016). However, management failings in Thai tourism stem from cultural traditions rather than government policies. In all of the tourist attractions examined during this investigation, local participation in tourism management was minimal or nonexistent. Bramwell and Lane (2013) have shown that the level of community participation is determined by social order, social coordination and social practices. In a hierarchical society like Thailand, participation in tourism management is restrictive and exclusive (Palmer \& Chuamuangphan, 2018). For tourist routes to be a success there should be an equal opportunities approach to involvement in heritage site management. There are multiple well-documented 
reasons for a lack of local engagement in participatory tourism, including low education, lack of time, absence of ownership, insufficient employment opportunities, imbalance benefit distribution and absence of necessary infrastructure (Kala \& Bagri, 2018; Kim, Park, \& Phandanouvong, 2014; Mustapha, Azman, \& Ibrahim, 2013; Saufi, O'Brien, \& Wilkins, 2014). However, unless the primary cultural obstacle of exclusion is overcome, the other barriers are irrelevant.

Cultivation of tourism awareness in the younger generations is crucial to ensure the long-term success of participatory tourism initiatives because they will inherit and continue any model developed today (Ernawati, Arjana, \& Nadra, 2021). This is particularly important in Northern Thailand, where younger generations are increasingly disregarding their traditional heritage in the face of global influences (Cohen, 2020). It is also important to empower youths for similar reasons of cultural hierarchy explained above. Studies of community-based tourism in Thailand have identified youth participation in tourism management as minimal (Sawatsuk, Darmawijaya, Ratchusanti, \& Phaokrueng, 2018; Somneuk, 2018). To cultivate awareness and ownership among young people, this researcher suggests a LUPAL model: Learning-Understanding-Passion-Action-Love. Learning is to provide youth with the opportunity to experience tourism and the culture of tourist attractions in their communities. Understanding is to provide opportunities and space for children and young people to participate in activities that develop self-understanding of tourism, culture and architectural value. Passion is developing pleasure, confidence and faith in community tourism practices. Action is giving opportunities for children and young people to take part and become responsible for small tourism projects that develop skills for future tourism management. Love is the condition developed after repeated participation in community tourism management.

When managed correctly, tourism development can have a positive impact on rural communities but there must be integrated planning through standardised procedures for the management of cultural routes as unified cultural systems, [which] can contribute to the sustainable protection and promotion of cultural heritage in rural areas, offering economic development, social cohesion' and conservation of natural resources (Oikonomopoulou, Delegou, Sayas, \& Moropoulou, 2017, p. 742). The most obvious and well-publicised case of the negative effects of tourism in Thailand is the environmental impact upon Maya Bay off Phi Phi Island, which was forced to close to visitors in 2019 (Koh \& Pipatpong, 2019). As the Northern Thai Lanna routes become more popular, management will become more important to ensure the longevity of the destinations, which is why zoning and the implementation of time and seasonal 
restrictions should be implemented. These are core elements of the six management practices recommended by informants of this investigation.

It is worth noting that Pattanaro and Pistocchi (2016) identified nine general components of successful cultural route planning: common theme, common goal, diversified destinations, comprehensive inventory, accessibility, clear communication, political support, funding, and continuous monitoring. The Northern Thai architectural routes developed as a consequence of this investigation synthesised each of these factors, with the exception of destination diversity. There is potential to develop these itineraries to incorporate routes designed for Northern Thai cuisine, natural environment and other region specific highlights (Sompong \& Rampai, 2015). This is recommended as an area for future investigation.

\section{Suggestions}

Following the results of this investigation, the researcher would like to give some suggestions. Firstly, public and private institutions should cooperate to create a community tourism network, inviting entrepreneurs and agencies interested in issues of cultural tourism in the Lanna civilisation area. The network should be established as a mechanism for exchanging ideas and offering operational support within the group. Secondly, the development of knowledge in cultural tourism should be supported in the local community through educational workshops to teach people about the architectural value of Lanna structures and the potential benefit of tourism services. Thirdly, links between communities and city development organisations should be fostered to drive tourism, promote local products and create tourism revenue. Fourthly, there should be training led by local educational institutions to develop and extend tourism products and create added value in tourism. Finally, training should be provided to build understanding about community-based tourism management in order to enable communities to participate more efficiently in the future.

\section{Acknowledgement}

The authors would like to thank the Thailand Research Fund for supporting this investigation. The grant number for this investigation is RDG5950051. 


\section{References}

Bramwell, B., \& Lane, B. (2013). Tourism Governance: Critical Perspectives on Governance and Sustainability. London: Routledge.

Briedenhann, J., \& Wickens, E. (2004). Tourism Routes as a Tool for the Economic Development of Rural Areas - Vibrant Hope or Impossible Dream? Tourism Management, 25(1), 71-79.

Calderwood, L., \& Soshkin, M. (2019). The Travel \& Tourism Competitiveness Report 2019: Travel and Tourism at a Tipping Point. Geneva: World Economic Forum.

Chulalongkorn University and the Department of Tourism. (2007). A Guide to Assessing the Quality Standards of Cultural Tourism [in Thai] [online]. Retrieved 9 July 2020, from file:///C:/Users/david.c/Downloads/Ebook09072020.pdf

Cohen, A. (2020). Youth Culture and Identity in Northern Thailand: Fitting in and Sticking Out. London: Routledge.

Council of Europe. (2002). Cultural Routes of the Council of Europe Programme. Retrieved 8 July 2020, from https://www.coe.int/en/web/culturalroutes/about

Denstadli, J. M., \& Jacobsen, J. K. S. (2011). The Long and Winding Roads: Perceived Quality of Scenic Tourism Routes. Tourism Management, 32(4), 780-789.

Devkota, N., Paudel, U. R., \& Bhandari, U. (2020). Tourism Entrepreneurs' Expectation from the Provincial Government in Touristic City Pokhara, Nepal. Journal of Hospitality and Tourism Insights, 3(3), 329-351.

Ernawati, N. M., Arjana, I. W. B., \& Nadra, N. M. (2021). Forest Supports Living on Earth: Awareness of the Youth at Jembrana Regency Bali Province Indonesia. International Journal of Green Tourism Research and Applications, 3(1), 35-39.

Fang, W. T. (2020). Cultural Tourism. In W. T. Fang (Ed.), Tourism in Emerging Economies (pp. 75-101). Singapore: Springer.

Festa, G., Shams, S. R., Metallo, G., \& Cuomo, M. T. (2020). Opportunities and Challenges in the Contribution of Wine Routes to Wine Tourism in Italy - A Stakeholders' Perspective of Development. Tourism Management Perspectives, 33(1). https://doi.org/10.1016/j.tmp.2019.100585.

Kala, D., \& Bagri, S. C. (2018). Barriers to Local Community Participation in Tourism Development: Evidence from Mountainous State 
Uttarakhand, India. Turizam: međunarodni znanstveno-stručni časopis, 66(3), 318-333.

Kim, S., Park, E., \& Phandanouvong, T. (2014). Barriers to Local Residents' Participation in Community-Based Tourism: Lessons from Houay Kaeng Village in Laos. SHS Web of Conferences, 12, 1-8.

Koh, E., \& Pipatpong, F. (2019). Overcoming “Over-Tourism”: The Closure of Maya Bay. International Journal of Tourism Cities, 6(2), 279-296.

Mei, X. Y., Lerfald, M., \& Bråtå, H. O. (2017). Networking and Collaboration between Tourism and Agriculture: Food Tourism Experiences along the National Tourist Routes of Norway. Scandinavian Journal of Hospitality and Tourism, 17(1), 59-75.

Mousavi, S. S., Doratli, N., Mousavi, S. N., \& Moradiahari, F. (2016). Defining Cultural Tourism. International Conference on Civil, Architecture and Sustainable Development, 1(2), 70-75.

Murray, M., \& Graham, B. (1997). Exploring the Dialectics of Route-Based Tourism: the Camino de Santiago. Tourism Management, 18(8), 513-524. http://dx.doi.org/10.1016/S0261-5177(97)00075-7

Mustapha, N. A., Azman, I. \& Ibrahim, Y. (2013). Barriers to Community Participation in Tourism Development in Island Destinations. Journal of Tourism, Hospitality \& Culinary Arts, 5(1), 102-124.

Oikonomopoulou, E., Delegou, E. T., Sayas, J., \& Moropoulou, A. (2017). An Innovative Approach to the Protection of Cultural Heritage: The Case of Cultural Routes in Chios Island, Greece. Journal of Archaeological Science: Reports, 14(1), 742-757.

Olsen, M. (2003). Tourism Themed Routes: A Queensland Perspective. Journal of Vacation Marketing, 9(4), 331-341.

Palmer, N. J., \& Chuamuangphan, N. (2018). Governance and Local Participation in Ecotourism: Community-Level Ecotourism Stakeholders in Chiang Rai Province, Thailand. Journal of Ecotourism, 17(3), 320-337.

Pattanaro, G., \& Pistocchi, F. (2016). Linking Destinations through Sustainable Cultural Routes. Symphonya: Emerging Issues in Management, 1(1), 83-96. Phuwanatwichit, T., Songthanapithak, A., Srirat, S., \& Sangkam, S. (2019). The Development of Integral Tourism Marketing Plan for Establishing Chiang Rai Province as a Tourism Hub of Lanna Civilisation through the Tourist Behaviour and Perception of Tourism Public Relations Media. Journal of Human Sciences, 20(2), 11-39. 
Piboonrungroj, P., \& Sangkakorn, K. (2013). Tourism Logistics Management: A Case of Cultural Creative Tourism in Thailand. In Proceedings of the 1st World Conference on Hospitality, Tourism and Event Research and International Convention and Expo Summit (pp. 855-859). Retrieved 9 July 2020, from https://www.researchgate.net/profile/Pairach_Piboonrungroj/publicat ion/260001134_TOURISM_LOGISTICS_MANAGEMENT_A_CASE_O F_CULTURAL_CREATIVE_TOURISM_IN_THAILAND/links/02e7e5 2efe23039934000000.pdf

Richards, G. (2018). Cultural Tourism: A Review of Recent Research and Trends. Journal of Hospitality and Tourism Management, 36(1), 12-21.

Rogerson, C. M. (2007). Tourism Routes as Vehicles for Local Economic Development in South Africa: The Example of the Magaliesberg Meander. Urban Forum, 18(2), 49-68.

Sangkakorn, K. (2018). Development of Cultural Tourism Products for Value Added Improvement: Case Study of Lanna Civilisation Route [in Thai]. Bangkok: Thailand Science Research and Innovation.

Sawatsuk, B., Darmawijaya, I. G., Ratchusanti, S., \& Phaokrueng, A. (2018). Factors Determining the Sustainable Success of Community-Based Tourism: Evidence of Good Corporate Governance of Mae Kam Pong Homestay, Thailand. International Journal of Business and Economic Affairs, 3(1), 13-20.

Saufi, A., O'Brien, D., \& Wilkins, H. (2014). Inhibitors to Host Community Participation in Sustainable Tourism Development in Developing Countries. Journal of Sustainable Tourism, 22(5), 801-820.

Schuhbert, A., Thees, H., Herbold, V., Weinreiter, J., \& Kantsperger, M. (2020). Cultural Tourism Routes as Incubators for Innovation and Economic Diversification: A Potential Analysis in the Framework of the New Silk Road Initiative in Azerbaijan. Zeitschrift für Wirtschaftsgeographie, 64(4), 211-232.

Sirikudta, S., Archarungroj, P., \& Sirisuthikul, V. (2019). Sustainable Creative Tourism for Fulfilling the Gap between Tourists' Expectation and Perception towards Tourism Routes in the Upper Greater Mekong Subregion. International Journal of Humanities, Arts and Social Sciences, 5(2), 43-53.

Sompong, N., \& Rampai, N. (2015). Knowledge Management of Thai Local Food on the Route of Northern Tourism in Thailand. International Journal of Information and Education Technology, 5(9), 664-667. 
Wattanacharoensil, W., \& Schuckert, M. (2016). Reviewing Thailand's Master Plans and Policies: Implications for Creative Tourism? Current Issues in Tourism, 19(10), 1045-1070.

Urošević, N., \& Kaurin, T. (2017). European Cultural Routes - Routes of Fortified Architecture. In N. Urošević \& K.A. Rakitovac (Eds.), Models of Valorisation of Cultural Heritage in Sustainable Tourism (pp. 135-159). Zagreb: Juraj Dobrila University of Pula.

Yiamjanya, S. (2019). The Study of Thai Self-Driving Tourists' Motivation Travel Planning Behaviour and Spatial Factor Effect on Planning Behaviour and Experience for Tourism Logistics Development: A Case Study of the Northern Thailand Routes. Sripratum Chonburi Journal, 15(4), 11-23.

Cite this article (APA):

Auttarat, S, Sangkakorn, K \& Krajangchom, S. (2021). The Enhancement of Cultural Tourism Routes in the Lanna Region of Northern Thailand. JATI-Journal of Southeast Asian Studies, 26(1), 124-140

Date received: 20 February 2021

Date of acceptance: 20 June 2021 